\title{
Prevalence and Factors Associated With Elder Abuse in Community-Dwelling Elderly in Korea: Mediation Effects of Social Support
}

\author{
Yu Jeong Lee ${ }^{1}$, Yong Kim², and Jong-II Park ${ }^{1,3 凶}$ \\ ${ }^{1}$ Department of Psychiatry, Jeonbuk National University Medical School, Jeonju, Republic of Korea \\ ${ }^{2}$ Department of Psychiatry, Presbyterian Medical Center, Jeonju, Republic of Korea \\ ${ }^{3}$ Research Institute of Clinical Medicine of Jeonbuk National University-Biomedical Research Institute of Jeonbuk National University Hospital, \\ Jeonju, Republic of Korea
}

\begin{abstract}
Objective The objectives of this study were to investigate the factors associated with elder abuse and the mediation effects of social support in a community-dwelling elderly population in Korea.

Methods This study analyzed a dataset of 10,674 individuals aged 65 years and older in Korea. Data were reviewed from a study conducted by the Korea Institute for Health and Social Affairs in 2011.

Results In our study, $12.6 \%$ of the elderly reported elder abuse, and $29.2 \%$ reported having depression (a score $\geq 8$ on the short version geriatric depression scale). Our results revealed that younger age, low economic status, poor social support (odds ratio [OR]=1.448) and depression $(\mathrm{OR}=2.039)$ were significantly associated with elder abuse after controlling for all confounding factors. In addition, mediation analysis showed that the OR for depression was reduced from 2.124 to 2.039 after social support was controlled, which indicates that the association between depression and elder abuse is partially mediated by social support.

Conclusion Depression and lack of social support were associated with abuse in community-dwelling Korean elderly. In particular, social support was revealed to buffer the association between depression and elder abuse.

Psychiatry Investig 2021;18(11):1044-1049

Key Words Elder abuse; Depression; Social support.
\end{abstract}

\section{INTRODUCTION}

Elder abuse is a serious problem that requires worldwide attention. The World Health Organization (WHO) and the United Nations (UN) emphasized the issue of elder abuse in previous reports. ${ }^{1,2}$ Elder abuse is defined as a single or repeated act, or lack of appropriate action, occurring within any relationship where there is an expectation of trust, which causes harm or distress to an older person. ${ }^{3}$ Elder abuse includes physical, psychological, financial, and/or sexual abuse as well as neglect. The impact of elder abuse is serious and poses risks that negatively affect physical and mental health in the elder-

Received: May 13, 2021 Revised: June 29, 2021

Accepted: July 18, 2021

$\triangle$ Correspondence: Jong-Il Park, MD, PhD

Department of Psychiatry, Jeonbuk National University Medical School, 20 Geonji-ro, Deokjin-gu, Jeonju 54907, Republic of Korea

Tel: +82-63-250-2577, Fax: +82-63-275-3157, E-mail: gofandf@naver.com

(c) This is an Open Access article distributed under the terms of the Creative Commons Attribution Non-Commercial License (https://creativecommons.org/licenses/bync/4.0) which permits unrestricted non-commercial use, distribution, and reproduction in any medium, provided the original work is properly cited. ly. It is also associated with increased unfavorable consequences such as premature morbidity and hospitalization. ${ }^{4-6}$

The aging population in Korea is growing more rapidly than that of the United States, France, and other developed countries, and it is predicted that Korea will transition from an aged society to a super-aged society over an eight-year duration. ${ }^{7}$ In 2019, the population of individuals older than 65 years in Korea was $14.9 \%$, which was much higher than in the worldwide population (9.1\%). In addition, the elderly population in Korea is anticipated to increase to $46.5 \%$ by 2067 . Since the elderly population is increasing so rapidly, the incidence of elder abuse is expected to increase. Many elderly individuals suffer from physical, mental, and financial problems such as chronic disease, loneliness, disability, and dementia. It seems that Korean society will face an unprecedented increase in the number of older adults and many associated dilemmas. Consequently, the elderly need various types of support from their families and society as a whole. International researches indicate that social support is considered as a potential protective factors against elder abuse and is inversely associated 
with depression symptoms. ${ }^{8-10}$ Previous research also suggests considerable mediation effect of social support between elder abuse and depressive symptoms, ${ }^{11}$ which means that the association between elder abuse and depression can be buffered by social support.

Over the past decades, substantial research has been conducted on elder abuse in Western countries and in some Asian countries. Unfortunately, there is scarcity of data in the literature investigating issues about elder abuse in Korea, as well as data to support the design of effective prevention programs. This study aimed to investigate the relationship between elder abuse and depression, and mediation effect of social support against elder abuse in a large representative communitydwelling elderly sample in Korea. To our best knowledge, the sample size of this study is the largest of its kind at the community level.

\section{METHODS}

The present study analyzed the dataset of the Survey of Living Conditions and Welfare Needs of Korean Older Persons in 2011 (Korea Institute for Health and Social Affairs), a government-approved survey (Statistics Korea, approval No. 11771). ${ }^{12}$ This survey has been conducted every three years since 2008, with representative samples using a stratified, twostage cluster sampling design of non-institutionalized elderly people. The survey collected information via face-to-face interviews. All participants gave written informed consent. A total of 11,542 elderly older than 60 years completed the survey (response rate $=76.2 \%$ ). The analysis was limited to 10,674 elderly older than 65 years. The present study was approved by the Ethics Committee of Jeonbuk National University Hospital (CUH 2021-03-024).

Each participant was asked about their experience of elder abuse, including physical, psychological, and/or financial abuse, as well as neglect during the past year. The experience of elder abuse was assessed by the following questions: "Have you ever been physically hurt by another?," "Have you ever been emotionally hurt by other's words or actions?", "Have you ever been financially damaged by another?", "Have you ever been neglected by another?" The possible responses for each question were yes and no. The participants who answered yes to one or more questions were included in the study.

The present study collected data about participant sociodemographic information (age, gender, living alone, educational status, economic status), health-related variables (number of chronic illnesses, functional impairment), social support, and depression. The number of chronic illnesses was gathered via following the question: "Do you currently have a chronic illness that has lasted for more than 3 months that was diagnosed by a physician?" The chronic illnesses included hyperlipidemia, hypertension, ischemic heart disease, and stroke. The number of chronic illnesses was categorized into none, one, two, or three or more. Functional impairment was defined as need for help with personal care in at least one item in the Korean Instrumental Activities of Daily Living (K-IADL). ${ }^{13}$ These activities are categorized into 10 domains of personal grooming, housework, preparing meals, doing laundry, going out for a short distance, using transportation, shopping, managing money, using a telephone, and taking medicine.

Social support was assessed via the following question: "How many close friends and relatives do you have (people you can talk to about what is on your mind)?" Social support was dichotomized into two groups (none vs. one or more). Depression in the elderly was assessed by the Korean version of the short Geriatric Depression Scale (SGDS), a 15-item administered questionnaire whose total score ranges from 0 to 15. ${ }^{14,15}$ Participants who scored higher than a cut-off score of 8 were defined as having depression, and this score indicates high sensitivity $(0.8548)$ and specificity $(0.6957)$ for depression based on a previous study. ${ }^{15}$

Descriptive statistics including frequency and percentage were used to describe sociodemographic, health-related, and psychological variables among the participants. Univariate analyses were performed to identify associations between elder abuse (without elder abuse/with elder abuse) and each dependent variable using the chi-square test. Multivariate logistic regression analysis was used to calculate the adjusted OR of elder abuse after controlling for confounding variables. Logistic regression analysis was used to calculate unadjusted and adjusted OR with $95 \%$ confidence interval (CI). Separate univariate logistic regressions were used to estimate the crude ORs of elder abuse to all independent variables investigated. Multivariate logistic regressions were used to calculate the adjusted ORs of elder abuse by including all independent variables simultaneously into the regression model. The level of significance was set at 5\%, and a two-tailed test was used.

\section{RESULTS}

Univariate analyses revealed independent variables associated with elder abuse (Table 1). Participants experiencing elder abuse were more likely to be female, live alone, be less educated, have a low economic status and less social support, have chronic illness, be IADL impaired, and/or have depression. Of the 10,539 elderly participants assessed in the present study, $12.7 \%(\mathrm{n}=1,336)$ had experienced abuse during the last year. For each type of abuse, the prevalence of physical abuse was $0.5 \%(n=52)$, that of emotional abuse was $9.4 \%(n=$ 990), that of financial abuse was $1.5 \%(\mathrm{n}=153)$, and that of ne- 
Table 1. Sociodemographic, health-related and psychological characteristics of participants

\begin{tabular}{|c|c|c|c|}
\hline & \multicolumn{2}{|c|}{ Elder abuse } & \multirow{2}{*}{ p-value } \\
\hline & No & Yes & \\
\hline $\operatorname{Sex}(N, \%)$ & & & 0.007 \\
\hline Male & $4,017(43.6)$ & $531(39.7)$ & \\
\hline Female & $5,187(56.4)$ & $805(60.3)$ & \\
\hline Age $(\mathrm{N}, \%)$ & & & 0.693 \\
\hline $65-69$ yrs & $2,739(29.8)$ & $411(30.8)$ & \\
\hline $70-74$ yrs & $2,813(30.6)$ & $411(30.8)$ & \\
\hline $75-79$ yrs & $2,084(22.6)$ & $306(22.9)$ & \\
\hline $80-84$ yrs & $1,019(11.1)$ & $140(10.5)$ & \\
\hline $85+$ yrs & $546(5.9)$ & $68(5.1)$ & \\
\hline Living alone (N, \%) & & & $<0.001$ \\
\hline No & $7,448(80.9)$ & $1,005(75.3)$ & \\
\hline Yes & $1,755(19.1)$ & $330(24.7)$ & \\
\hline \multicolumn{4}{|l|}{ Educational status (N, \%) } \\
\hline No education & $2,844(30.9)$ & $480(36.0)$ & \\
\hline 6 yrs or less & $3,328(36.2)$ & $416(31.2)$ & \\
\hline $7-12$ yrs & $2,361(25.7)$ & $376(28.2)$ & \\
\hline 13 yrs or more & $671(7.3)$ & $63(4.7)$ & \\
\hline Economic status (N, \%) & & & $<0.001$ \\
\hline 1st quintile & $1,752(19.0)$ & $358(26.8)$ & \\
\hline 2nd quintile & $1,839(20.0)$ & $281(21.0)$ & \\
\hline 3rd quintile & $1,851(20.1)$ & $249(18.7)$ & \\
\hline 4th quintile & $1,880(20.4)$ & $234(17.5)$ & \\
\hline 5th quintile & $1,882(20.4)$ & $213(16.0)$ & \\
\hline Social support (N, \%) & & & $<0.001$ \\
\hline 1 or more & $1,564(17.0)$ & $329(24.6)$ & \\
\hline No & $7,637(83.0)$ & $75.4(1007)$ & \\
\hline Chronic disease (N, \%) & & & $<0.001$ \\
\hline None & $1,030(11.2)$ & $109(8.2)$ & \\
\hline 1 & $1,785(19.4)$ & $239(17.9)$ & \\
\hline 2 & $2,300(25.0)$ & $254(19.0)$ & \\
\hline 3 or more & $4,089(44.4)$ & $733(54.9)$ & \\
\hline IADL (N, \%) & & & $<0.001$ \\
\hline No & $8,059(87.6)$ & $1,125(84.3)$ & \\
\hline Yes & $9,197(12.4)$ & $1,335(15.7)$ & \\
\hline Depression (N, \%) & & & $<0.001$ \\
\hline Negative & $6,630(72.1)$ & $704(52.7)$ & \\
\hline Positive (GDS $\geq 8$ ) & $2,562(27.9)$ & $1,335(47.3)$ & \\
\hline
\end{tabular}

IADL, instrumental activities of daily living; GDS, Geriatric Depression Scale

glect was $2.9 \%(\mathrm{n}=306)$.

From multiple logistic regression analysis, age, education, economic status, social support, chronic disease, and depression were associated with elder abuse. Older age showed less

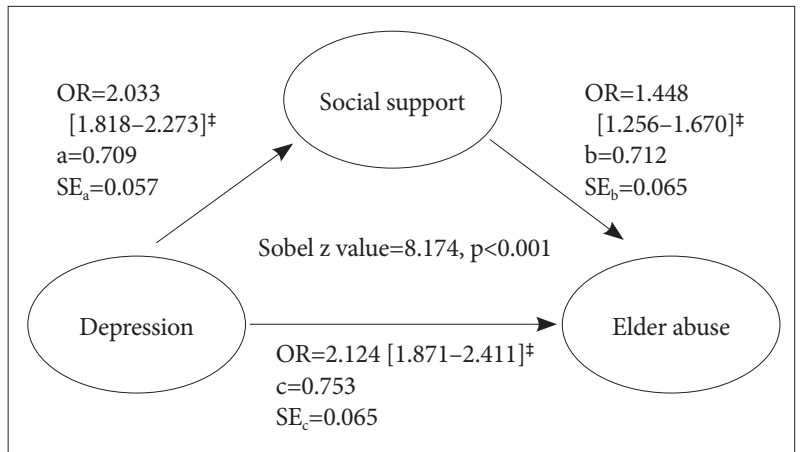

Figure 1. Mediation effect of social support on depression and elder abuse. OR for abuse decreased from 2.214 [1.871, 2.411] to $2.039[1.794,2.419]^{\ddagger}$ when social support was included in multivariate logistic regression analysis. To test mediation effect, we calculated Sobel test value with OR, path coefficient and standard error (SE). The value was $8.174(p<0.001)$ which was higher than 1.96 suggesting a meaningful mediation effect of social support. $\neq p<0.001$.

association with elder abuse. OR was 0.849 ( $95 \% \mathrm{CI}=0.730$, $0.988)$ for age group $70-74,0.775(0.655,0.917)$ for age group $75-79,0.683(0.549,0.851)$ for age group $80-84$, and 0.617 $(0.460,0.826)$ for age group 85 or older. Regarding education level, elders with nine to 11 years of education showed a higher OR of $1.220(1.026,1.450)$ in contrast to those with six to less than nine years of education or with 12 or more years of education. Higher economic status was less associated with elder abuse of $0.683(0.548,0.852)$ for the 5th quintile and $0.794(0.658,0.957)$ for the 1st quintile. Having three or more chronic illnesses increased the OR of elder abuse by 1.355 $(1.083,1.696)$. Poor social support also increased elder abuse $[\mathrm{OR}=1.448(1.256,1.670)]$. Functional impairment, gender, and living alone were not associated with elder abuse.

Figure 1 illustrates the results of the mediation analyses evaluating whether social support affected the association between depression and elder abuse. Regression results are displayed in Table 2. Depression was predictive of elder abuse $(\mathrm{OR}=2.214,95 \% \mathrm{CI}=1.871,2.411, \mathrm{p}<0.001)$ and of poor social support ( $\mathrm{OR}=2.033,95 \% \mathrm{CI}=1.818,2.273, \mathrm{p}<0.001)$. After controlling for depression, poor social support remained predictive of elder abuse $(\mathrm{OR}=1.448,95 \% \mathrm{CI}=1.256,1.670, \mathrm{p}<0.01)$; however, OR for depression decreased from $2.214(95 \% \mathrm{CI}=$ $1.871,2.411, \mathrm{p}<0.001)$ to 2.039 ( $95 \% \mathrm{CI}=1.794,2.419, \mathrm{p}<0.001)$. This indicates that the influence of depression on elder abuse is mediated partially by social support. To test the mediation effect, we calculated the Sobel test value, which was 8.174 $(\mathrm{p}<0.001)$. The value was higher than 1.96 , which suggests a meaningful mediation effect of social support. ${ }^{16}$

\section{DISCUSSION}

This study aimed to investigate prevalence and associated 
Table 2. Multiple logistic regression analysis of variables affecting elder abuse

\begin{tabular}{|c|c|c|}
\hline & \multicolumn{2}{|c|}{ Elder abuse OR [95\% CI] } \\
\hline & Model 1 & Model 2 \\
\hline \multicolumn{3}{|l|}{ Sex } \\
\hline Male & - & - \\
\hline Female & $1.035[0.901,1.189]$ & $1.046[0.910,1.201]$ \\
\hline \multicolumn{3}{|l|}{ Age } \\
\hline $65-69$ yrs & - & - \\
\hline $70-74$ yrs & $0.858[0.737,0.998]^{*}$ & $0.849[0.730,0.988]^{*}$ \\
\hline $75-79$ yrs & $0.789[0.667,0.933]^{\dagger}$ & $0.775[0.655,0.917]^{\dagger}$ \\
\hline $80-84$ yrs & $0.700[0.562,0.871]^{\dagger}$ & $0.683[0.549,0.851]^{\dagger}$ \\
\hline $85+$ yrs & $0.639[0.477,0.855]^{\dagger}$ & $0.617[0.460,0.826]^{\dagger}$ \\
\hline \multicolumn{3}{|c|}{ Living alone (N, \%) } \\
\hline No & - & - \\
\hline Yes & $1.071[0.901,1.272]$ & $1.103[0.928,1.312]$ \\
\hline \multicolumn{3}{|c|}{ Educational status (N, \%) } \\
\hline No education & - & - \\
\hline 6 yrs or less & $0.851[0.732,0.991]^{*}$ & $0.858[0.737,0.999]^{*}$ \\
\hline $7-12$ yrs & $1.195[1.006,1.420]^{*}$ & $1.220[1.026,1.450]^{*}$ \\
\hline 13 yrs or more & $0.875[0.648,1.183]$ & $0.900[0.666,1.216]$ \\
\hline \multicolumn{3}{|l|}{ Economic status } \\
\hline 1st quintile & - & - \\
\hline 2nd quintile & $0.794[0.658,0.957]^{*}$ & $0.796[0.660,0.961]^{*}$ \\
\hline 3rd quintile & $0.763[0.624,0.934]^{\dagger}$ & $0.768[0.627,0.939]^{*}$ \\
\hline 4th quintile & $0.710[0.575,0.875]^{\dagger}$ & $0.725[0.587,0.895]^{\dagger}$ \\
\hline 5th quintile & $0.683[0.548,0.852]^{\dagger}$ & $0.693[0.556,0.864]^{\dagger}$ \\
\hline \multicolumn{3}{|c|}{ Social support (people) } \\
\hline 1 or more & - & - \\
\hline No & - & $1.448[1.256,1.670]^{\ddagger}$ \\
\hline \multicolumn{3}{|l|}{ Chronic disease } \\
\hline None & - & - \\
\hline 1 & $1.243[0.975,1.584]$ & $1.244[0.976,1.586]$ \\
\hline 2 & $0.942[0.740,1.199]$ & $0.948[0.745,1.208]$ \\
\hline 3 or more & $1.355[1.083,1.696]^{\dagger}$ & $1.385[1.106,1.733]^{\dagger}$ \\
\hline \multicolumn{3}{|l|}{ IADL } \\
\hline No & - & - \\
\hline Yes & $1.065[0.895,1.268]$ & $1.016[0.852,1.211]$ \\
\hline \multicolumn{3}{|l|}{ Depression } \\
\hline Negative & - & - \\
\hline Positive & $2.124[1.871,2.411]^{\ddagger}$ & $2.039[1.794,2.317]^{\ddagger}$ \\
\hline
\end{tabular}

${ }^{*} \mathrm{p}<0.05 ;{ }^{\dagger} \mathrm{p}<0.01 ;{ }^{\ddagger} \mathrm{p}<0.001$. OR, odds ratio; CI, confidence interval; IADL, instrumental activities of daily living

factors of elder abuse. The overall prevalence of elder abuse in this study was $12.6 \%$ in community-dwelling Koreans, which was similar to $15.7 \%$ from a recent meta-analysis. ${ }^{17}$ The results of the multivariate regression analysis after controlling confounding variables revealed that depression, poor social support, chronic illness, younger age, and low economic status were associated factors of elder abuse, among which depression showed the greatest odds ratio $(\mathrm{OR}=2.039)$. In addition, the impact of depression on elder abuse was mediated partially by social support.

In our study, a substantial proportion of elderly (29.2\%) had depression, a result comparable to the prevalence found in a previous nationwide survey of elderly depression (27.8\%) in Korea. ${ }^{18}$ The rate of depressed individuals who experienced elder abuse was much higher than that in those who did not experience depression ( $47.3 \%$ vs. $27.9 \%)$. The OR for elder abuse significantly increased by more than two times for those with depression compared to those without depression. The association of depression with elder abuse was consistent with the results of previous studies. In a population-based study of 10,419 elders enrolled in the Chicago Health and Aging Project, participants with higher depressive symptoms were more likely to experience elder abuse. ${ }^{19}$ In a cross-sectional study in China, the prevalence of depression was $12 \%$, and the prevalence of elder abuse was $35 \% .^{20,21}$ Dissatisfaction with life, being bored, and feeling helpless or worthless increased the OR for elder abuse. It has been reported that elderly who experienced abuse showed significantly higher prevalence of depression ( $62 \%$ vs. $12 \%$ ) than those who had no experience of abuse. ${ }^{21}$ Depression is a potentially harmful condition in the elderly, causing negative effects such as interpersonal problems, increase in both medical comorbidity and medical risk factors, worsening of cognitive impairment, impairment of mobility, excess disability, and increased mortality (both from suicide and from the interactions between depression and medical illnesses). ${ }^{22}$ Depression can lead to suicidal ideation and attempts in severe cases. In addition, abused elderly with depressive symptoms showed increased mortality risk and a hazard ratio of 2.60 for the highest levels of depressive symptoms, in a large community study in the USA..$^{23}$ There is an increasing need to enhance public awareness of elder abuse and to increase government and professional concern about the issue. Based on the possibility of recovery from depression through various approaches, such as pharmacotherapy and psychosocial therapy, it is important to offer treatment opportunities and a systematic approach to treating elderly with depression and abuse experience. In addition, screening for depressed elderly individuals who suffer from elder abuse and developing preventive strategies could reduce the distress caused by elder abuse.

In our result, social support was a significant associated factor of elder abuse after adjustment for confounding variables. This finding is consistent with many previous studies. A U.S. 
study found that low social support was strongly associated with emotional, physical, and sexual abuse. ${ }^{24}$ Social support was a protective factor in a cross-sectional study of a Chinese population that visited a major urban medical center in China. ${ }^{25}$ Comijs et al. ${ }^{26}$ studied the effect of social support on elder abuse and concluded that social support showed a favorable effect on victims compared to non-victims. These results support a decrease in elder abuse with increased social support. In addition, our results suggest that the association between depression and elder abuse is mediated partially by social support. This finding also supports the evidence of previous studies. Dong et al. ${ }^{27}$ evaluated the effects of social support on depression and elder mistreatment in 411 community dwelling Chinese individuals who presented to a medical center and concluded that social support has a modifying effect on depression and elder abuse. Vilar-Compte et al. ${ }^{28}$ studied 526 elderly women who attended public community centers and concluded that social support has a mediation effect on depression and elder abuse. Elders with poor social support are more likely to be socially isolated and show poor health behaviors. ${ }^{29}$ It seemed that poor social support can increase the vulnerability of elders to stressful life events such as abuse and contribute to delays in seeking help. Also, various depressive symptoms such as depressed mood, decreased motivation, and worthlessness can lead abused elderly to become socially withdrawn and inhibit detection of abuse. Our results suggest that enhancing social support resources in the elderly could serve as a buffer between depression and elder abuse. In preventing elder abuse, social support should be carefully monitored, and strategies focusing on increasing support from various public and private sectors should be emphasized.

In our study, having three or more chronic diseases, lower economic status, and younger age were associated with elder abuse. However, the result is not consistent with other studies. There were relatively consistent results about the association between chronic disease and elder abuse. Poor physical health had strong evidence in its association with elder abuse in studies conducted in India and the United States. ${ }^{24,30}$ Acute change in management of chronic disease was suggested as a possible indicator of elder abuse. ${ }^{31}$ Low income was associated with elder abuse in studies conducted in Mexico, Ireland and India. ${ }^{28,30,32}$ Marguerite DeLiema studied elder abuse among lowincome immigrant Latinos and found higher rates of abuse and neglect than other community dwelling elders. ${ }^{33}$ Low-income elders tend to be economically dependent on their extended families. Women are more vulnerable to elder abuse than men in countries including India and Mexico. ${ }^{30,34}$ Younger age was associated with higher risk of elder abuse in the United States. ${ }^{24}$ In contrast to our study, those 80 years or older in Ireland experienced a higher level of elder abuse com-

pared to other age groups. ${ }^{32}$ There are relatively consistent results about chronic disease as a risk factor in elder abuse. Elders with chronic disease need more attention regarding the risk of abuse, such as economic status, age and gender.

A strength of this study was the large representative sample of elderly aged 65 years or older. This study also had some limitations. First, it was a cross-sectional study, so the results do not consider temporal relationships. A prospective study about associated factors of elder abuse is required to examine the causal effects. Second, the study evaluated the presence of abuse by self-report, allowing participants to answer in a socially acceptable manner, which can cause self-report bias. Third, community level associated factors such as cultural norms were not considered, which could affect the measurement of selfreporting social support and elder abuse. Fourth, this study didn't consider cognitive impairment which can have a significant impact in the elderly. Further research which takes better account of these limitations is needed.

Relatively little is known about the factors associated with elder abuse in Korea. The elderly population in Korea will increase rapidly to $37 \%$ of the total population by 2045 . In our study, significant factors associated with elder abuse were depression, social support, and chronic illnesses, and social support partially mediated the association between depression and elder abuse. Targeted prevention strategies focusing on these associated factors could reduce the distress from elder abuse.

\section{Availability of Data and Material}

The datasets generated or analyzed during the study are available from the corresponding author on reasonable request.

\section{Conflicts of Interest}

The authors have no potential conflicts of interest to disclose.

\section{Author Contributions}

Conceptualization: Jong-Il Park. Data curation: Jong-Il Park. Formal analysis: Jong-Il Park. Funding acquisition: Jong-Il Park. Investigation: all authors. Methodology: all authors. Project administration: Jong-Il Park. Resources: Jong-Il Park. Software: Jong-Il Park. Supervision: Jong-Il Park. Validation: Jong-Il Park. Visualization: all authors. Writing_original draft: all authors. Writing_review \& editing: all authors.

\section{ORCID iDs}

Yu Jeong Lee Yong Kim Jong-Il Park

https://orcid.org/0000-0001-6987-1021 https://orcid.org/0000-0001-6465-209X https://orcid.org/0000-0003-4690-397X

\section{Funding Statement}

This paper was supported by Fund of Biomedical Research Institute, Jeonbuk National University Hospital.

\section{REFERENCES}

1. Global Status Report on Violence Prevention 2014. Geneva: World Health Organization; 2014. 
2. Human Rights of Older Persons: Summary of the Report of the Secretary-General to the General Assembly (Report A/66/173). New York: Office of the UN High Commissioner for Human Rights; 2010.

3. Toronto Declaration on the Global Prevention of Elder Abuse. Geneva: World Health Organization; 2002;3.

4. Dong X. Medical implications of elder abuse and neglect. Clin Geriatr Med 2005;21:293-313.

5. Dong X, Simon M, Mendes de Leon C, Fulmer T, Beck T, Hebert L, et al. Elder self-neglect and abuse and mortality risk in a communitydwelling population. JAMA 2009;302:517-526.

6. Dong X, Simon MA.Elder abuse as a risk factor for hospitalization in older persons. JAMA Intern Med 2013;173:911-917.

7. The Aged Statistics. Daejeon: Korea National Statistical Office; 2010.

8. Ganster DC, Victor B. The impact of social support on mental and physical health. Br J Med Psychol 1988;61:17-36.

9. Acierno R, Hernandez MA, Amstadter AB, Resnick HS, Steve K, Muzzy W, et al. Prevalence and correlates of emotional, physical, sexual, and financial abuse and potential neglect in the United States: the National Elder Mistreatment Study. Am J Public Health 2010;100:292-297.

10. García-Peña C, Wagner FA, Sánchez-Garcia S, Juárez-Cedillo T, Espinel-Bermúdez C, García-Gonzalez JJ, et al. Depressive symptoms among older adults in Mexico City. J Gen Intern Med. 2008;23:1973-1980.

11. Vilar-Compte M, Giraldo-Rodríguez L, Ochoa-Laginas A, Gaitan-Rossi P. Association between depression and elder abuse and the mediation of social support: a cross-sectional study of elder females in Mexico City. J Aging Health 2018;30:559-583.

12. Jung KH, Lee YK, Park BM, Lee SJ, Lee YH. Analysis of the Survey of Living Conditions and Welfare Needs of Korean Older Persons. Sejong: Korea Institute for Health and Social Affairs; 2012.

13. Won CW, Yang KY, Rho YG, Kim SY, Lee EJ, Yoon JL, et al. The Development of Korean Activities of Daily Living (K-ADL) and Korean Instrumental Activities of Daily Living (K-IADL) Scale. J Korean Geriatr Soc 2002;6:107-120.

14. Sheikh J, Yesavage J, Brink T. Recent Evidence and Development of a Shorter Version. Clinical Gerontology: A Guide to Assessment and Intervention. London: Título do livro; 1986.

15. Bae JN, Cho MJ. Development of the Korean version of the Geriatric Depression Scale and its short form among elderly psychiatric patients. J Psychosom Res 2004;57:297-305.

16. Baron RM, Kenny, David A. The moderator-mediator variable distinction in social psychological research: Conceptual, strategic, and statistical considerations. J Pers Soc Psychol 1986;51:1173-1182.

17. Yon Y, Mikton CR, Gassoumis ZD, Wilber KH. Elder abuse prevalence in community settings: a systematic review and meta-analysis. Lancet Glob Health 2017;5:e147-e156.

18. Park JH, Kim KW, Kim MH, Kim MD, Kim BJ, Kim SK, et al. A nationwide survey on the prevalence and risk factors of late life depression in South Korea. J Affect Disord 2012;138:34-40.

19. Roepke-Buehler SK, Simon M, Dong X. Association between depres- sive symptoms, multiple dimensions of depression, and elder abuse: a cross-sectional, population-based analysis of older adults in urban Chicago. J Aging Health 2015;27:1003-1025.

20. Dong X, Simon MA, Odwazny R, Gorbien M. Depression and elder abuse and neglect among a community-dwelling Chinese elderly population. J Elder Abuse Neglect 2008;20:25-41.

21. Dyer CB, Pavlik VN, Murphy KP, Hyman DJ. The high prevalence of depression and dementia in elder abuse or neglect. J Am Geriatr Soc 2000;48:205-208.

22. Reynolds CF 3rd. Prevention of depressive disorders: a brave new world. Depress Anxiety 2009;26:1062-1065.

23. Dong XQ, Simon MA, Beck TT, Farran C, McCann JJ, Mendes de Leon $\mathrm{CF}$, et al. Elder abuse and mortality: the role of psychological and social wellbeing. Gerontology 2011;57:549-558.

24. Acierno R, Hernandez MA, Amstadter AB, Resnick HS, Steve K, Muzzy $\mathrm{W}$, et al. Prevalence and correlates of emotional, physical, sexual, and financial abuse and potential neglect in the United States: The National Elder Mistreatment Study. Am J Public Health 2010;100:292-297.

25. Dong X, Simon MA. Is greater social support a protective factor against elder mistreatment? Gerontology 2008;54:381-388.

26. Comijs HC, Penninx BW, Knipscheer KP, van Tilburg W. Psychological distress in victims of elder mistreatment: the effects of social support and coping. J Gerontol B Psychol Sci Soc Sci 1999;54:P240-P245.

27. Dong X, Beck T, Simon MA. The associations of gender, depression and elder mistreatment in a community-dwelling Chinese population: The modifying effect of social support. Arch Gerontol Geriatr 2010;50: 202-208.

28. Vilar-Compte M, Giraldo-Rodríguez L, Ochoa-Laginas A, Gaitan-Rossi P. Association between depression and elder abuse and the mediation of social support: a cross-sectional study of elder females in Mexico City. J Aging Health 2018;30:559-583.

29. Luo Y, Hawkley LC, Waite LJ, Cacioppo JT. Loneliness, health, and mortality in old age: a national longitudinal study. Soc Sci Med 2012;74:907914.

30. Chokkanathan S, Lee AEY. Elder mistreatment in urban India: a community based study. J Elder Abuse Negl 2005;17:45-61.

31. LoFaso VM, Rosen T. Medical and Laboratory Indicators of Elder Abuse and Neglect. Clin Geriatric Med 2014;30:713-728.

32. Naughton C, Drennan J, Lyons I, Lafferty A, Treacy M, Phelan A, et al. Elder abuse and neglect in Ireland: results from a national prevalence survey. Age Ageing 2011;41:98-103.

33. DeLiema M, Gassoumis ZD, Homeier DC, Wilber KH. Determining prevalence and correlates of elder abuse using promotores: low-Income immigrant latinos report high rates of abuse and neglect. J Am Geriatr Soc 2012;60:1333-1339.

34. Giraldo-Rodríguez L, Rosas-Carrasco O. Development and psychometric properties of the Geriatric Mistreatment Scale. Geriatr Gerontol Int 013;13:466-474. 